\title{
Fisiologia do Exercício para alunos de graduação: uso de estratégias de ensino baseadas na metodologia dialética
}

\author{
CDD. 20.ed. 378 \\ 613.7 \\ 796.022
}

Christiano Robles Rodrigues ALVES*

Juliane Cruz CAMPOS*

José Bianco Nascimento MOREIRA*

Thaís Simões NOBRE**

Iris Callado SANCHES ${ }^{* * *}$

Cláudia Lúcia de Moraes FORJAZ*

Patrícia Chakur BRUM ${ }^{*}$
*Escola de Educação Física e Esporte,

Universidade de São

Paulo.

**Faculdade de Medicina, Universidade de São Paulo.

***Universidade Nove de Julho.

\section{Resumo}

A metodologia dialética propõe um ensino de dupla mão (professor-aluno) que provoque a aprendizagem por meio de tarefas contínuas dos sujeitos. Para isso, o professor assume o papel de mediador e dirige as diferentes atividades. Nesse contexto, a Fisiologia do Exercício é uma disciplina academicamente orientada que está inserida em um ambiente dinâmico, e a utilização de estratégias de ensino se faz necessária para otimizar a apropriação do conhecimento de forma ativa, além de contribuir para a maior autonomia dos estudantes universitários. Portanto, o objetivo do presente estudo foi o de utilizar diferentes estratégias de ensinagem por meio de atividades propostas aos alunos na disciplina de Fisiologia da Atividade Motora I da Escola de Educação Física e Esporte da Universidade de São Paulo e correlacionar o desempenho do aluno com a sua participação nessas atividades propostas. Nossos principais achados demonstram correlações significativas e positivas entre a presença nas aulas e o desempenho nas avaliações ( $p<$ $0,0001 ; r=0,84)$, bem como entre a realização das atividades propostas e o desempenho nas avaliações $(p<0,0001 ; r=0,69)$. Em conjunto, esses dados sugerem que a utilização de diferentes estratégias de ensinagem baseadas na metodologia dialética com a ativa participação dos alunos é essencial para um bom rendimento acadêmico, sendo altamente recomendada para o ensino da Fisiologia do Exercício.

Palavras-chave: Esporte; Educação física; Ensino.

\section{Introdução}

Os elementos principais de discussão da ação docente são o ensino e a aprendizagem. Apesar de considerarmos que essas ações devam ocorrer conjuntamente no decorrer do desenvolvimento de uma disciplina, muitas vezes elas ocorrem disjuntas $^{1}$. Segundo Anastasiou e Alves ${ }^{1}$, isso decorre da visão tradicional de que ensinar seria o equivalente a exposição ou apresentação de um conteúdo pelo docente (metodologia expositiva) e caberia ao aluno aprendê-lo ou não. Nesse contexto, o professor seria o responsável por explicar o conteúdo, cabendo ao aluno assistir as aulas e memorizar o conteúdo exposto. Diante dessa visão, o docente seria o detentor do conhecimento teórico-prático que vai traduzir ao aluno. Por sua vez, o aluno seria um assistente passivo das explanaçóes do professor.

Embora esse modelo de ensino ainda vigore na maioria dos cursos de graduação e tenha sido vivenciado pela grande maioria dos docentes que hoje atuam no ensino superior, o mesmo parece não ser o mais efetivo para o processo ensino-aprendizagem. Em contraste, o uso de estratégias pedagógicas que tratem a ação de ensinar em sua abrangência, que vai desde a intencional de ensinar do professor até a de apreensão e apropriação do conhecimento por parte dos alunos, tem sido utilizadas para a efetivação do ensino ${ }^{1-3}$.

O termo "ensinagem" propõe uma situação de ensino na qual o professor considera em suas estratégias 
tanto o processo de ensino quanto o processo de aprendizagem, denotando que uma parceria professoraluno é fundamental no processo educacional ${ }^{1}$. Nesse contexto, nos deparamos com metodologia dialética que, diferentemente da metodologia expositiva tradicional, propõe que o conhecimento não é apenas transferido, mas sim construído conjuntamente pelo professor e o aluno em um ensino de mão-dupla (professor-aluno e vice-versa). Para isso, o professor assume o papel de mediador e dirige as atividades e ações nas tarefas e estratégias propostas, levando em consideração as três fases propostas na metodologia dialética, a saber: a) síncrese, momento de mobilização para o conhecimento objetivando aproximação entre aluno e objeto de estudo; b) análise, momento de construção do conhecimento; e c) síntese, momento de sistematização do conhecimento que vem sendo adquirido $\mathrm{o}^{4-5}$

O objetivo do presente estudo foi o de utilizar diferentes estratégias de ensinagem por meio de

\section{Método}

\section{Sujeitos}

A amostra foi composta por 100 alunos que cursaram a disciplina de "Fisiologia da Atividade Motora I" na EEFE-USP durante o primeiro semestre do ano de 2011. Todos os alunos estavam regularmente matriculados em cursos de graduação da Universidade de São Paulo, a saber: 42 alunos no curso Núcleo Básico em Educação Física; 51 alunos no curso de Bacharelado em Esporte; seis alunos no curso de Fisioterapia e um aluno no curso de Ciências Biológicas. Além disso, os anos de ingresso de cada aluno em seus respectivos cursos foram: $2010(\mathrm{n}=63$ alunos); 2009 ( $\mathrm{n}=15$ alunos); 2008 ( $\mathrm{n}=12$ alunos); 2007 ( $\mathrm{n}=6$ alunos); 2006 ( $\mathrm{n}=2$ alunos); e 2004 ( $\mathrm{n}=$ 2 alunos). Cabe ressaltar que no currículo dos cursos Núcleo Básico em Educação Física e Bacharelado em Esporte, o $3^{\circ}$ semestre é considerado ideal para cursar a disciplina. Portanto os ingressantes em 2010 cursaram a disciplina no semestre ideal.

A disciplina foi dividida em duas turmas, que denominaremos como Turma I e Turma II. A Turma I foi composta por 46 alunos, dos quais $91,3 \%(\mathrm{n}=$ 42) estavam matriculados no curso Bacharelado em Esporte; 6,5 \% (n=3) no curso Fisioterapia; e 2,2 \% $(\mathrm{n}=1)$ no curso Ciências Biológicas. Enquanto que a Turma II foi composta por 54 alunos, dos quais 77,8 atividades propostas aos alunos na disciplina de Fisiologia da Atividade Motora I (disciplina oferecida para os cursos de Bacharelado e Licenciatura em Educação Física e Bacharelado em Esporte da USP) e correlacionar o desempenho do aluno com a sua participação nessas atividades propostas. Cabe ressaltar que as atividades foram vinculadas às três fases da metodologia dialética, como a elaboração de mapas conceituais e aula expositiva dialogada para a fase de síncrese; aula expositiva dialogada, aulas práticas, conversas com especialistas, estudo do meio e estudo de textos científicos para a fase de análise; e estudo dirigido e estudo de casos para a fase de síntese.

Esse estudo integrou as atividades dos alunos de pós-graduação bolsistas do Programa de Aperfeiçoamento ao ensino (PAE-CAPES) na disciplina e de um aluno bolsista do Programa de Estímulo ao Ensino de Graduação (PEEG) da Pró-Reitoria de Graduação da Universidade de São Paulo.

$\%(\mathrm{n}=42)$ estavam matriculados no curso Núcleo Básico em Educação Física; 16,7 \% ( $\mathrm{n}=9)$ no curso Bacharelado em Esporte; e 5,5 \% $(n=3)$ no curso Fisioterapia. Em suma, a Turma I era representada em sua maioria por alunos do curso Bacharelado em Esporte, enquanto que a Turma II por alunos do curso Núcleo Básico em Educação Física.

\section{Procedimentos}

Trata-se de um estudo de característica descritiva conduzido durante o primeiro semestre do ano de 2011, período no qual a disciplina "Fisiologia da Atividade Motora I" na EEFE-USP foi ministrada. O principal objetivo da disciplina foi discutir os efeitos fisiológicos agudos e crônicos do exercício físico no organismo, bem como os mecanismos responsáveis por esses efeitos, buscando a apropriação pelos alunos de conhecimentos atuais de Fisiologia do Exercício. Foram abordados temas relativos à fisiologia neuromuscular e cardiovascular durante o exercício físico, sendo o conteúdo da disciplina dividido em dois módulos, a saber: Módulo I- músculo esquelético e exercício físico; e Módulo II- sistema cardiovascular e exercício físico. Vale destacar que os módulos foram compostos por aulas presenciais com duração aproximada de duas horas e meia (divididas em duas 
partes de uma hora e 15 minutos, intercaladas por um intervalo de 20 minutos).

O Módulo I foi desenvolvido ao longo de sete semanas (incluindo sete aulas presenciais de duas horas e meia), nas quais as estratégias pedagógicas de ensino utilizadas foram: 1) aulas expositivas dialogadas (utilizada em todas as aulas); 2) aulas práticas para realização/ observação de experimentos (utilizada em duas aulas); 3) conversas com professores convidados especialistas em temas específicos (utilizada em duas aulas); 4) estudo dirigido (após todas as aulas); 5) estudo de textos científicos (duas resenhas de artigo e leitura para todas as aulas); e 6) estudo de casos (utilizados em duas aulas). Foi realizada avaliação continuada do módulo I que consistiu na participação e realização das tarefas propostas e uma prova dissertativa ao final do módulo I.
Posteriormente, o Módulo II se desenvolveu ao longo de nove semanas (incluindo nove aulas presenciais) e as estratégias pedagógicas de ensino empregadas foram: 1) elaboração de mapas conceituais (utilizada em duas aulas); 2) aulas expositivas dialogadas (utilizada em todas as aulas); 3) estudo de casos (utilizados em três aulas); 4) estudo do meio (utilizados em uma aula); 5) aulas práticas (utilizadas em três aulas); e 6) estudo de textos científicos (leitura recomendada para todas as aulas). Similarmente ao módulo I, foi realizada avaliação continuada do módulo II que consistiu na participação e realização das tarefas propostas e uma prova dissertativa ao final do módulo.

O QUADRO 1 descreve e exemplifica as estratégias pedagógicas de ensino utilizadas.

QUADRO 1-Estratégias pedagógicas de ensino utilizadas.

\begin{tabular}{|c|c|c|}
\hline Atividade & Descrição & Exemplos utilizados \\
\hline $\begin{array}{l}\text { Aulas expositivas } \\
\text { dialogadas }\end{array}$ & $\begin{array}{l}\text { Estratégia para superar a tradicional palestra } \\
\text { docente. A grande diferença entre elas é que } \\
\text { a participação do estudante é incentivada, ou } \\
\text { seja, ele tem suas observaçóes consideradas e } \\
\text { analisadas, independentemente da procedên- } \\
\text { cia e de sua pertinência. }\end{array}$ & $\begin{array}{l}\text { Essa ferramenta pedagógica foi utilizada para } \\
\text { expor e discutir os conceitos e novos conheci- } \\
\text { mentos em diversas aulas. }\end{array}$ \\
\hline $\begin{array}{l}\text { Aulas práticas } \\
\text { em sala de aula } \\
\text { e no laboratório }\end{array}$ & $\begin{array}{l}\text { Aprofundamento de conceitos previamente } \\
\text { adquiridos com a participaçáo dos estudantes } \\
\text { em experimentos e atividades práticas. }\end{array}$ & $\begin{array}{l}\text { Em laboratório, foram realizados experimen- } \\
\text { tos de histologia, eletroforese e função muscu- } \\
\text { lar "in vitro". Em sala de aula, foram realizados } \\
\text { experimentos para avaliaçáo dos efeitos agudos } \\
\text { do exercício físico sobre a pressão arterial e a } \\
\text { frequência cardíaca. }\end{array}$ \\
\hline $\begin{array}{l}\text { Conversas } \\
\text { com professores } \\
\text { convidados } \\
\text { especialistas }\end{array}$ & $\begin{array}{l}\text { Discussão de um tema específico com um es- } \\
\text { pecialista da área. }\end{array}$ & $\begin{array}{l}\text { Foram debatidos temas como: 1) os efeitos } \\
\text { concorrentes do treinamento físico de força } \\
\text { e aeróbio; 2) o treinamento com oclusão } \\
\text { vascular para ganho de força muscular; e 3) } \\
\text { treinamento funcional. }\end{array}$ \\
\hline Estudo dirigido & $\begin{array}{l}\text { Estudar sob a orientação do professor, visando } \\
\text { sanar dificuldades específicas. }\end{array}$ & $\begin{array}{l}\text { Foram elaborados roteiros para que os alunos } \\
\text { estudassem em grupos na própria sala de aula. } \\
\text { Além disso, foram realizados grupos de estudo } \\
\text { em horários alternativos com a participaçáo do } \\
\text { monitor e dos alunos PAE da disciplina. }\end{array}$ \\
\hline $\begin{array}{l}\text { Estudo de textos } \\
\text { científicos }\end{array}$ & $\begin{array}{l}\text { Exploração de ideias e resultados de um artigo } \\
\text { científico a partir do estudo crítico do texto el } \\
\text { ou na busca de informaçóes a respeito. }\end{array}$ & $\begin{array}{l}\text { Foram indicados artigos científicos relevantes } \\
\text { da área e solicitado que os alunos realizassem } \\
\text { uma resenha crítica dos mesmos e foram dis- } \\
\text { cutidos em aula. }\end{array}$ \\
\hline $\begin{array}{l}\text { Mapas } \\
\text { conceituais }\end{array}$ & $\begin{array}{l}\text { Construção de um diagrama que indica a relação } \\
\text { de conceitos em uma perspectiva bidimensional, } \\
\text { procurando mostrar as relaçôes hierárquicas en- } \\
\text { tre os conceitos pertinentes ao conteúdo. }\end{array}$ & $\begin{array}{l}\text { Os alunos foram divididos em grupos e construí- } \\
\text { ram mapas conceituais sobre o conteúdo do mó- } \\
\text { dulo II. Posteriormente, a sala inteira construiu } \\
\text { o mesmo mapa com mediação dos professores. }\end{array}$ \\
\hline
\end{tabular}


QUADRO 1-Estratégias pedagógicas de ensino utilizadas (continuação).

\begin{tabular}{|l|l|l|}
\hline Atividade & \multicolumn{1}{|c|}{ Descriçáo } & \multicolumn{1}{|c|}{ Exemplos utilizados } \\
\hline Estudo de casos & $\begin{array}{l}\text { Análise minuciosa e objetiva de uma situaçáo } \\
\text { real que necessita ser investigada, relacionan- } \\
\text { do-se os dados com os elementos da teoria es- } \\
\text { tudada. }\end{array}$ & $\begin{array}{l}\text { Foram propostos diversos estudos de casos no fi- } \\
\text { nal das aulas. Os casos foram discutidos na aula } \\
\text { seguinte. Utilizou-se muito esta estratégia para o } \\
\text { ensino de levantamento de fatores de risco car- } \\
\text { diovascular, interpretação de testes ergométricos } \\
\text { e prescriçáo de exercício físico por ergometria. }\end{array}$ \\
\hline Estudo do meio & $\begin{array}{l}\text { Estudo direto da realidade, propiciando a } \\
\text { aquisiçáo de conhecimentos de forma direta, } \\
\text { por meio da experiência prática vivida. }\end{array}$ & $\begin{array}{l}\text { Após discutir em aula os efeitos do treinamen- } \\
\text { to físico no sistema cardiovascular, a interpreta- } \\
\text { çáo de testes ergométricos e prescriçáo de exer- } \\
\text { cício físico por ergometria, os alunos visitaram } \\
\text { um programa de condicionamento físico para } \\
\text { prevenção cardiológica primária e secundária, } \\
\text { seguindo um roteiro de observaçáo que levou } \\
\text { em consideraçáo desde questóes relacionadas } \\
\text { a organizaçáo, estrutura e procedimentos do } \\
\text { Programa. Alunos acompanharam testes e ro- } \\
\text { tina das aulas e elaboraram relatório da visita. }\end{array}$ \\
\hline
\end{tabular}

O critério para aprovação na disciplina foi obter uma média final (média da avaliação dos dois módulos) maior ou igual a 5,0; e uma presença maior ou igual a $70 \%$ nas aulas. A equipe que ministrou a disciplina foi composta por duas professoras doutoras da própria Instituição, dois alunos de mestrado e dois de doutorado inscritos no programa de aperfeiçoamento de ensino (PAE-CAPES) da USP, além de um monitor (aluno do $8^{\circ}$ período do curso Bacharelado em Educação Física) envolvido no programa de estímulo ao ensino de graduação (PEEG) da PróReitoria de Graduação da própria Instituição.

\section{Resultados}

A FIGURA 1 ilustra a média final (obtida após a realização das duas avaliações somadas às tarefas extraclasse) para cada turma. Não houve diferença estatística quando comparadas as médias das Turmas I e II (6,5 $\pm 1,7$ ["range": 0,0 a 9,3] vs. $6,0 \pm 2,1$ ["range": 0,0 a 9,2]; p = 0,34). Sendo assim, todos os dados que seguem serão analisados e interpretados considerando as turmas conjuntamente (Turma I + Turma II).

Vale destacar que a presença nas aulas foi de 81,4 $\pm 18,2 \%$ ("range": 18,7 a 100\%); e a porcentagem de tarefas realizadas foi de 51,2 $\pm 29,6 \%$ ("range": 0 a $100 \%)$. Nesse contexto, $16 \%$ dos alunos ( $\mathrm{n}=$

\section{Análise estatística}

Os dados quantitativos estão expressos em média \pm desvio padrão ["range"]. Foi empregado teste t de Student para dados não pareados com a finalidade de comparar o desempenho entre as Turmas I e II. Além disso, foi utilizada a análise de regressão linear para avaliar associaçóes entre o desempenho nas avaliaçóes e a presença nas aulas, bem como o desempenho nas avaliações e a participação/desempenho nas tarefas propostas supracitadas. $\mathrm{O}$ nível de significância adotado para se rejeitar a hipótese nula foi de $\mathrm{p}<0,05$.

16) não atingiram os critérios para aprovação na disciplina, sendo $9 \%(n=9)$ devido a uma presença menor que $75 \%$ nas aulas presenciais.

A FIGURA 2 ilustra um histograma para a média final, a presença e o número de tarefas propostas extraclasse realizadas pelos alunos.

Como esperado, houve uma correlação alta e positiva entre a presença dos alunos nas aulas propostas (expositivas dialogadas e práticas) e a média final (FIGURA 3A). Uma correlação positiva também foi observada entre a participação dos alunos nas atividades propostas extraclasse e o desempenho nas avaliações da disciplina (FIGURA 3B). 


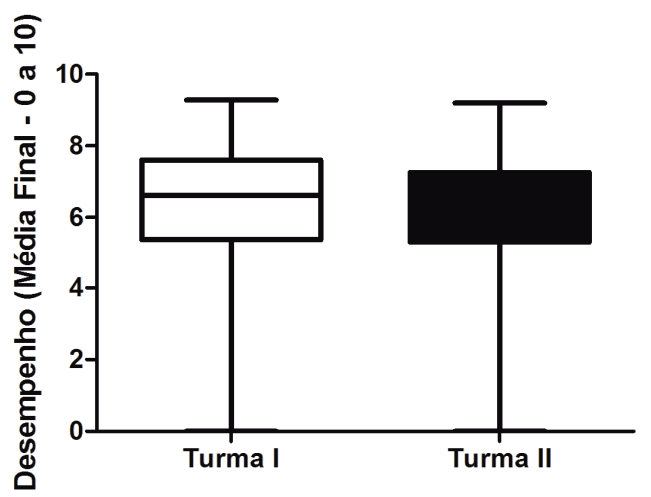

FIGURA 1 - Média final das Turmas I e II.
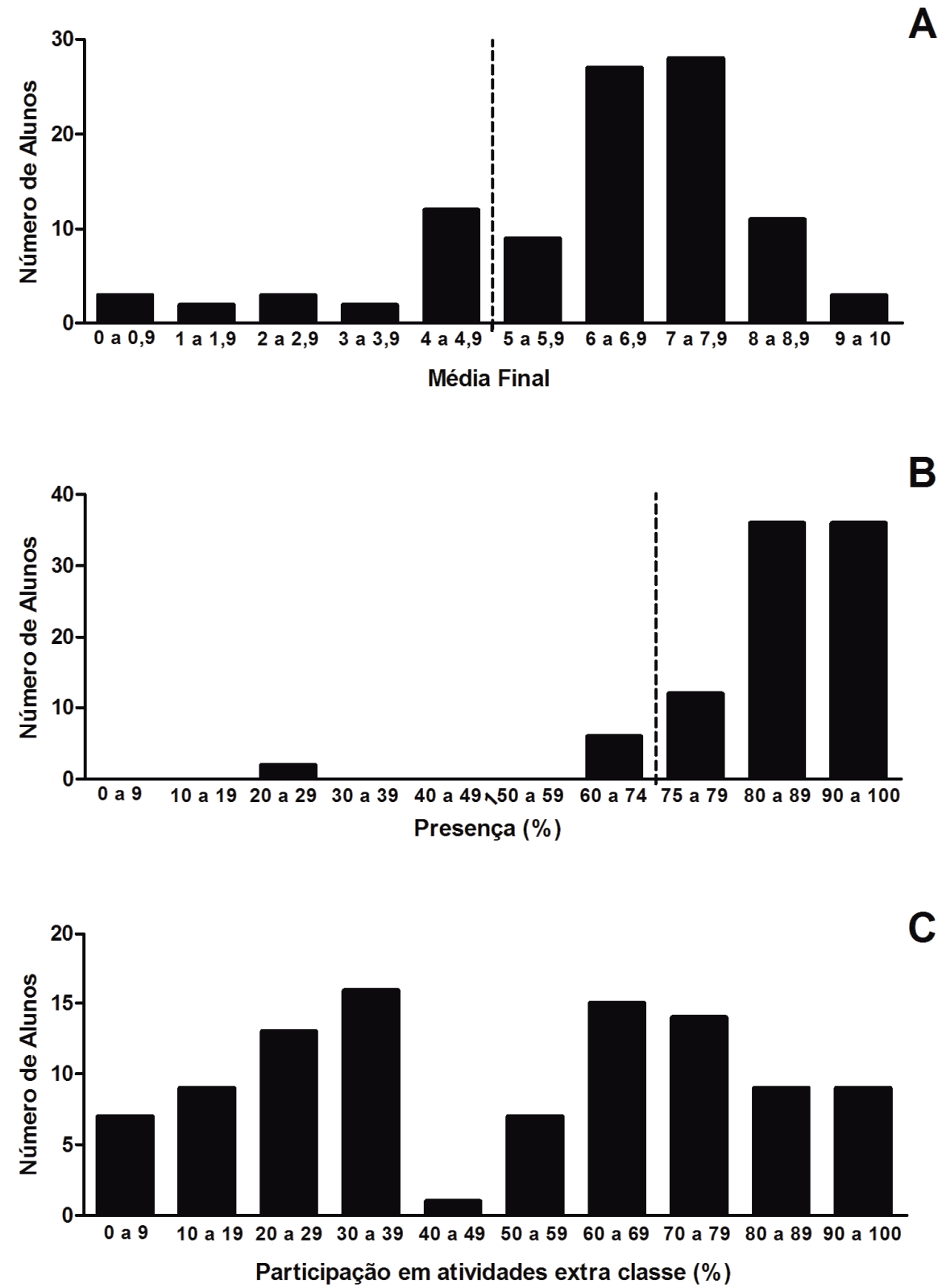

FIGURA 2 - Histogramas da Média Final (A), Presença (B) e participação dos alunos nas atividades propostas (C). 


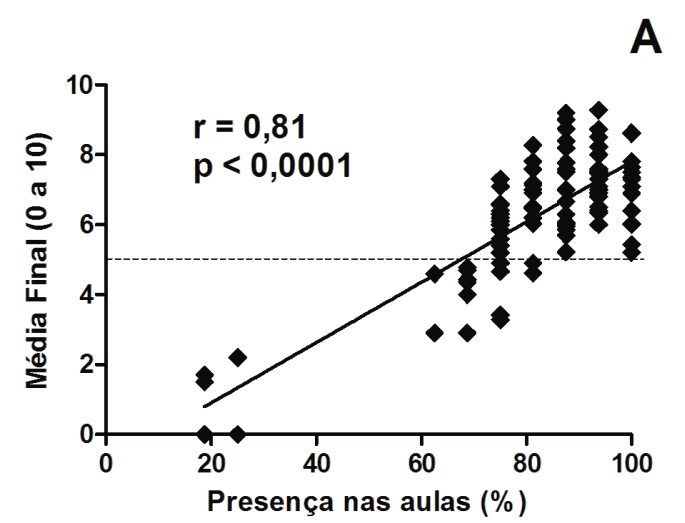

B

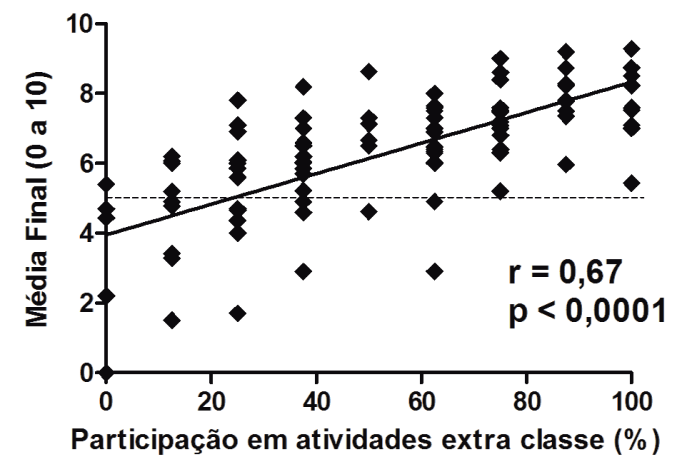

FIGURA 3 - Correlação entre a média final e a presença dos alunos nas aulas propostas (A) e entre a média final e a participação dos alunos nas atividades propostas extraclasse (B).

\section{Discussão}

Essa pesquisa descritiva teve como objetivo utilizar diferentes estratégias de ensinagem baseadas na metodologia dialética por meio de atividades propostas aos alunos na disciplina de Fisiologia da Atividade Motora I (disciplina oferecida para os cursos de Bacharelado e Licenciatura em Educação Física e Bacharelado em Esporte da USP) e correlacionar o desempenho do aluno com a sua participação nessas atividades propostas. Nossos principais achados foram correlações significantes e positivas entre a presença nas aulas e o desempenho nas avaliaçôes, bem como a entre a realização das tarefas propostas e o desempenho nas avaliações. Em conjunto, esses dados sugerem que a participação dos alunos em diferentes atividades auxilia no processo ensino-aprendizagem.

A utilização de estratégias que incentivem o ensino de mão dupla (professor-aluno e vice-versa), como na metodologia dialética, é essencial no processo educacional, contribuindo para o desenvolvimento do senso crítico nos alunos e a capacidade de continuar se atualizando na área após o término da disciplina. De fato, RuÉ denomina essa necessidade como formação em situação de autonomia.

No estudo de Ramsвотtom et al. ${ }^{3}$ foram utilizadas duas estratégias de ensinagem semelhantes a duas das utilizadas no presente estudo (estudo de texto científico e aula prática) na disciplina de Fisiologia do Exercício da Universidade de Oxford Brookes (Oxford, UK) ao longo de três anos consecutivos. Os alunos reproduziram protocolos clássicos da literatura para mensurar a capacidade e/ou potência aeróbia e anaeróbia uns nos outros. Posteriormente, eles realizaram regressōes lineares para estabelecer diferentes correlaçōes entre os parâmetros fisiológicos (e.g. consumo máximo de oxigênio) e o desempenho em testes físicos. Os autores reforçam que o fato de coletar, analisar e interpretar esses dados fez com que os alunos se apropriassem melhor dos conceitos abordados previamente na disciplina ${ }^{3}$. Como podemos observar, essas estratégias foram utilizadas em um momento da disciplina em que a construção (análise) e 
a síntese do conhecimento constituíram importantes fases para o processo de aprendizagem. Ao encontro desses achados, observamos uma alta correlação entre a porcentagem de alunos que realizaram as atividades propostas (e.g. estudo de textos científicos, a elaboração de mapas conceituais, os estudos de casos e os estudos do meio) e o desempenho nas avaliações.

A participação ativa dos alunos nas atividades propostas e interação com o professor são necessárias e reforçam a importância da presença dos mesmos nas aulas. Nesse sentido, a metodologia dialética propõe que o professor assuma o papel de mediador, dirigindo essas atividades e ações nas tarefas e estratégias propostas 5 . O presente estudo ressalta a importância das aulas presenciais, o que é sustentada pela alta e positiva correlação encontrada entre a presença nas aulas e o desempenho nas avaliaçóes. Algumas hipóteses podem ser levantadas na tentativa de explicar essa correlação, a saber: 1) a exposição do conhecimento nas aulas presenciais é uma importante forma de retê-lo; e 2) a mediação das discussões e orientação nas tarefas a serem executadas proporcionam um melhor aproveitamento das tarefas que serão realizadas extraclasse.

Especificamente em Fisiologia do Exercício, os conceitos são normalmente transmitidos aos alunos assumindo que eles serão capazes de fazer a síntese e integração necessária para a aplicação em situações específicas de exercício físico. Contudo, essa transição não é tão simples ${ }^{7}$. Segundo Mercuri e Polydoro ${ }^{8}$, nem sempre os alunos conseguem responder aos desafios de valores, atitudes e consensos que as experiências do contexto universitário oferecem, seja devido a características pessoais ou porque não encontraram apoio suficiente para o devido enfrentamento. Isso não surpreende, uma vez que a maioria dos alunos que hoje são universitários passou por um processo de ensino-aprendizagem onde o seu papel era o de ser ouvinte passivo das aulas do professor dificultando sua mobilização e adesão a atividades de ensinagem como as propostas no presente estudo. De fato, tivemos uma baixa adesão nas tarefas realizadas e isso pode ter contribuído para o desempenho final mediano dos alunos de ambas as turmas nessa disciplina. Assim, acreditamos que a média final poderia ter sido maior se tivéssemos uma melhor adesão por parte dos alunos. Nesse sentido, acreditamos que um melhor trabalho de sensibilização e conscientização dos alunos de graduação seja necessário na disciplina.

Como limitação, esse estudo não apresentou nenhuma condição comparativa com outras metodologias de ensino, sendo que estudos futuros devem ser conduzidos. Além disso, a ausência da avaliação diagnóstica/inicial é uma importante limitação do estudo. No entanto, nossos dados suportam que quanto maior a participação nas atividades propostas, melhor o desempenho dos alunos, sugerindo que a estratégia utilizada foi eficaz em melhorar o desempenho.

Em suma, os resultados do presente estudo sugerem que a utilização de diferentes estratégias de ensinagem baseadas na metodologia dialética com a ativa participação dos alunos é essencial para um bom rendimento acadêmico, sendo altamente recomendada para o ensino da Fisiologia da Atividade Motora na graduação.

\section{Abstract}

Exercise Physiology for undergraduates: the use of teaching strategies basead on the dialectical method

The dialectic method proposes a two-way teaching (teacher-student) that causes learning through ongoing task of the subjects. For this, the teacher assumes the role of mediator and directs several activities. In line with the above, Exercise Physiology is an academically oriented discipline undergoing in a dynamic environment, and the use of different teaching strategies is needed to optimize the appropriation of knowledge in an active way and contribute to the greater autonomy of university students. Therefore, the aim of this study was apply different strategies in the course entitled "Physiology of the Motor Activity I" at School of Physical Education and Sport of University of Sao Paulo and assess a correlation between students participation and students performance. We used teaching strategies such as exposition and dialogue classes, practical classes, conversations with experts, directed study, study of scientific texts, concept mapping, case study and study of the environment in order to optimize the appropriation of the concepts of exercise physiology with emphasis on neuromuscular and cardiovascular physiology exercise. Our main findings show significant and positive correlations between the presence in classes and the performance 
evaluations $(p<0.0001, r=0.84)$ as well as between the tasks proposed and the performance evaluations $(p<0.0001 ; r=0.69)$. Altogether, these data suggest that using different teaching strategies based on the dialectic method associated with the participation of students is essential for a good academic performance in Exercise Physiology.

KeY WORDS: Sport; Physical education; Education.

\section{Referências}

1. Anastasiou LGC, Alves LP. Processos de ensinagem na universidade. 8a ed. Joinville: Univille; 2009.

2. Alves LP, Anastasiou LGC. 3 Estratégias de ensinagem. In: Anastasiou LGC. Processos de ensinagem na universidade: pressupostos para as estratégias de trabalho em aula. Joinville: Univille; 2007.

3. Ramsbottom R, Kinch RFT, Morris MG, Dennis AM. Practical application of fundamental concepts in exercise physiology. Adv Physiol Educ. 2007;31:347-51.

4. Vasconcelos CS. Metodologia dialética em sala de aula. Rev Educ AEC. 1992; Disponível em: http://www.celsovasconcellos.com.br/Textos/MDSA-AEC.pdf.

5. Vasconcelos CS. Construção do conhecimento em sala de aula. São Paulo: Liberdad; 1994.

6. Rué J. A aprendizagem com autonomia, possibilidade e limites. In: Pimenta SG, Almeida MI. Pedagogia universitária. São Paulo: Editora da Universidade de São Paulo; 2009.

7. Franchini E, Takito MY, Bertuzzi R. Fisiologia do exercício para estudantes de educação física: uma análise quantitativa de dois métodos de exposição de conteúdos. Rev Mackenzie Educ Fís Esporte. 2008;7:17-25.

8. Mercuri E, Polydoro SAJ. Estudante universitário: características e experiências de formação. Taubaté: Cabral; 2004.

\begin{tabular}{r|l} 
ENDEREÇo & \\
Christiano Robles Rodrigues Alves & \\
Escola de Educação Física e Esporte - USP & Recebido para publicação: 13/04/2012 \\
Av. Prof. Melo Moraes, 65 & Revisado: 03/08/2012 \\
05508-030 - São Paulo - SP - BRASIL & Aceito: 28/02/2013 \\
e-mail: christiano.alves@usp.br & \\
&
\end{tabular}

296 • Rev Bras Educ Fís Esporte, (São Paulo) 2013 Abr-Jun; 27(2):289-96 